\title{
Isomer Separation and Gas-Phase Configurations of Organoruthenium Anticancer Complexes: Ion Mobility Mass Spectrometry and Modeling
}

\author{
Jonathan P. Williams, ${ }^{\text {a }}$ Tijana Bugarcic, ${ }^{\text {a Abraha Habtemariam, }}{ }^{\text {a }}$ \\ Kevin Giles, ${ }^{\mathrm{b}}$ Iain Campuzano, ${ }^{\mathrm{b}}$ P. Mark Rodger, ${ }^{\mathrm{a}}$ and Peter J. Sadler ${ }^{\mathrm{a}}$ \\ ${ }^{a}$ Department of Chemistry, University of Warwick, Coventry, United Kingdom \\ ${ }^{\mathrm{b}}$ Waters Corporation, Manchester, United Kingdom
}

We have used ion mobility-mass spectrometry combined with molecular modeling for the separation and configurational analysis of three low-molecular-weight isomeric organoruthenium anticancer complexes containing ortho-, meta-, or para-terphenyl arene ligands. The isomers were separated using ion mobility based on traveling-wave technology and the experimentally determined collision cross sections were compared to theoretical calculations. Excellent agreement was observed between the experimentally and theoretically derived measurements. (J Am Soc Mass Spectrom 2009, 20, 1119-1122) (c) 2009 American Society for Mass Spectrometry

$\mathrm{T}$ The application of electrospray ionization (ESI) mass spectrometry (MS) to organometallic chemistry and its development toward the characterization of organometallic species has been the focus of previous studies [1-3]. ESI is a gentle ionization technique, capable of transferring preformed ions from solution into the gas phase, and has been used in previous investigations of the interaction of organometallic-based anticancer drugs and biomolecules $[4,5]$. The platinum-based drug, cisplatin [cis-diamminedichloridoplatinum(II)], for example, falls into this category and is one of the leading drugs used in the fight against cancer. DNA is a potential target for many metal-based anticancer drugs and distortions of DNA structure often correlate with anticancer activity. Other metal-based anticancer drugs, such as those based on ruthenium, are being developed as alternative treatments to combat cancer. In particular, the aim is to widen the spectrum of anticancer activity, reduce unwanted side effects, and avoid crossresistance with cisplatin and related drugs. Insights into the physical size and shape of these novel Ru-based drugs are important for elucidation of structureactivity relationships and for optimizing key interactions such as intercalation into DNA $[6,7]$. Here we explore three novel isomeric Ru-based anticancer drugs using a combined ion mobility and mass spectrometry (IM-MS) approach.

Address reprint requests to Dr. Jonathan Paul Williams, University of Warwick, Department of Chemistry, Gibbet Hill Road, Coventry CV4 7AL, UK. E-mail: j.p.williams@warwick.ac.uk
As a stand-alone technique, MS cannot separate isomeric species or provide bulk structural conformational information. However, IM has the ability to rapidly separate isomeric species (on the MS acquisition timescale) based on differences in their collision cross sections (CCSs; physical size and shape) in the gas phase, thus providing specific information on ionic configuration [8-11]. The combination of IM with MS provides an extremely powerful analytical tool.

To investigate the possible benefits of the IM-MS technique, an instrument that is based around "travelingwave" (T-wave) mobility separation [12-14] has been used for the first time to analyze a mixture of three low-molecular-weight isomeric ruthenium terphenyl anticancer complexes $\left(\mathrm{m} / \mathrm{z} 427.1\right.$ based on ${ }^{102} \mathrm{Ru}$, labeled $\mathbf{1}, \mathbf{2}$, and $\mathbf{3}$ in Figure 1a). The study has allowed us to probe the individual differences in shape in an attempt to correlate them with differences in anticancer activity. Molecular modeling was also used to generate a range of possible structures and the theoretical CCSs for these structures were calculated for comparison with experimentally derived T-wave values. Excellent agreement was observed between the experimentally and theoretically derived CCS measurements.

\section{Experimental}

Preparation of Samples for IM-MS

Complexes 1, 2, and 3 (Figure 1a) were dissolved in methanol to a concentration of $1 \mathrm{ng} / \mu \mathrm{L}(\sim 2 \mu \mathrm{M})$ before 
(a)
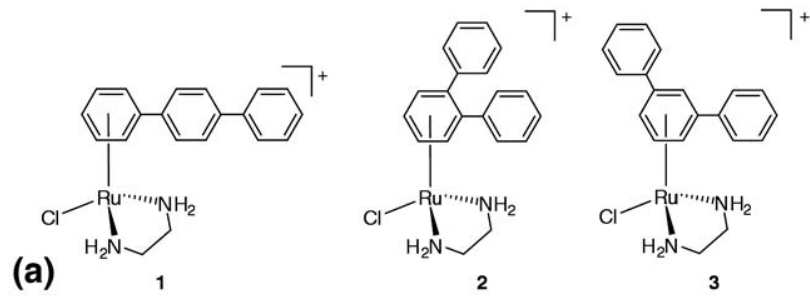

$[\mathrm{M}-\mathrm{HCl}]^{+}$

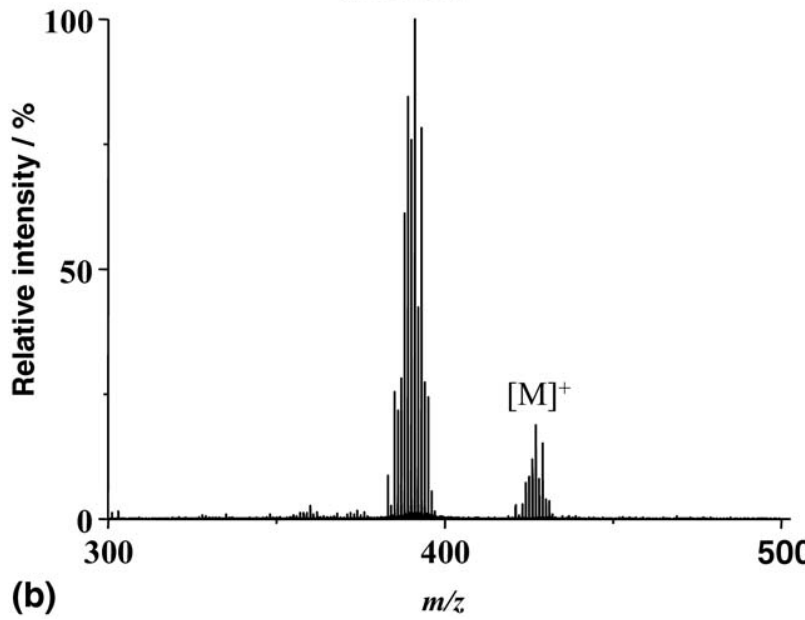

Figure 1. (a) The organometallic terphenyl ruthenium-based anticancer complexes analyzed in this study and (b) the ESI mass spectrum of a $1 \mathrm{ng} / \mu \mathrm{L}$ (methanol) solution of complex 1 .

infusion at $5 \mu \mathrm{L} / \mathrm{min}$ into the source of the mass spectrometer. (See Section S1 in the supplementary material, which may be found in the electronic version of this article.)

\section{Hybrid Quadrupole/Ion Mobility/OA-ToF MS Instrumentation}

Experiments were performed using a Waters (Manchester, UK) Synapt HDMS (high-definition mass spectrometer) instrument. This instrument, described in detail elsewhere [12], has a hybrid quadrupole/ion mobility/ orthogonal acceleration time-of-flight (OA-ToF) geometry. Ions are accumulated and periodically released into the mobility T-wave cell, where they separate according to their mobility through action of a continuous train of transient voltage pulses (traveling waves). Mobility spectra are obtained by sequentially recording 200 ToF mass spectra following the release of the ion packet into the mobility cell. The instrument was operated in electrospray positive-ion mode with a capillary voltage of $3.0 \mathrm{kV}$. The mobility T-wave cell was operated at 2.1 mbar of nitrogen with a wave velocity of 300 $\mathrm{m} / \mathrm{s}$ and wave height of $28.4 \mathrm{~V}$ for optimal separation of the isomeric terphenyl complexes. A wave height of 20 $\mathrm{V}$ was used for optimal separation of the $\mathrm{HCl}$ neutral loss species. Data acquisition and processing were carried out using MassLynx (V4.1, Waters) software supplied with the instrument.
The approach to calculation of collision cross-section values from the T-wave mobility device is explained in Section S2 of the supplementary material.

\section{Computation}

The coordinates obtained from X-ray crystallographic measurements were used for molecular dynamics simulations of more than 170,000 bimolecular collisions between the molecular ion and He. These simulations were used for generation of the lowest energy conformation of the isomeric species. Initial He positions were selected at random from a spherical shell centered on the molecular ion and inner radius of $20 \AA$; atomic velocities were selected at random from a Boltzmann distribution corresponding to $298 \mathrm{~K}$ and a drift velocity of $40 \mathrm{~m} / \mathrm{s}$ (the average drift velocity in the experiments) added to all atoms in the molecular ion. The molecular ion was modeled using the CHARMs force field, including all intramolecular degrees of freedom [16] with $\mathrm{He} /$ molecular ion potentials taken from MOBCAL [17]. Simulations were implemented in DL_POLY [18] using a 0.5 -fs time step, the NVE ensemble, and no periodic boundaries. CCSs were estimated using the open source software program MOBCAL [17, 19]. Briefly, the MOBCAL output is based on three different models, which calculate the theoretical collisional cross section of any molecule possessing a three-dimensional coordinate file. These models are the projection approximation (PA), exact hard sphere scattering (EHSS), and the trajectory method (TM) [19]. The values obtained from the three MOBCAL algorithms were then compared to the T-wave-derived CCSs.

\section{Results and Discussion}

Isomeric terphenyl complexes of the type $\left[\left(\eta^{6}\right.\right.$-arene $)$ $\mathrm{Ru}(\mathrm{en}) \mathrm{Cl}]^{+}$, where the arene is para- (1), ortho- (2), or meta-terphenyl (3) ( $p$-, o-, or $m$-terp; Figure 1a) were synthesized to investigate the effect on cytotoxicity of the additional phenyl ring in comparison to biphenyl (bip) complexes that we have previously studied in detail [20, 21]. See Section S3 in the supplementary material for further discussion.

Isomeric complexes 1, 2, and $\mathbf{3}$ were detected at $\mathrm{m} / \mathrm{z}$ 427.1 (Figure $1 \mathrm{~b}$ ) corresponding to $[\mathrm{M}]^{+}$. This mass spectrum is representative of the three complexes under the instrumental parameters used. The base peak in each of the mass spectra corresponded to the neutral loss of $\mathrm{HCl}$ at $\mathrm{m} / \mathrm{z}$ 391.1. The mobility spectrum obtained for $m / z 427.1$ from a mixture of complexes 2 and 1 showed distinct peaks with a $0.55-\mathrm{ms}$ difference in drift times (4.17 ms for 2 and $4.72 \mathrm{~ms}$ for $\mathbf{1}$; Figure $2 \mathrm{~b}$ ). A slightly smaller difference of $0.5 \mathrm{~ms}$ was observed for the mixture of $\mathbf{3}$ and $\mathbf{1}$ (4.22 ms for $\mathbf{3}$ and $4.72 \mathrm{~ms}$ for $\mathbf{1}$; Figure 2c). With all three isomeric complexes mixed together, 2 and 3 merged into one peak with drift time centered around $4.22 \mathrm{~ms}$. In Figure 2d, the drift time for complex 2 alone (dashed line) is compared with the 

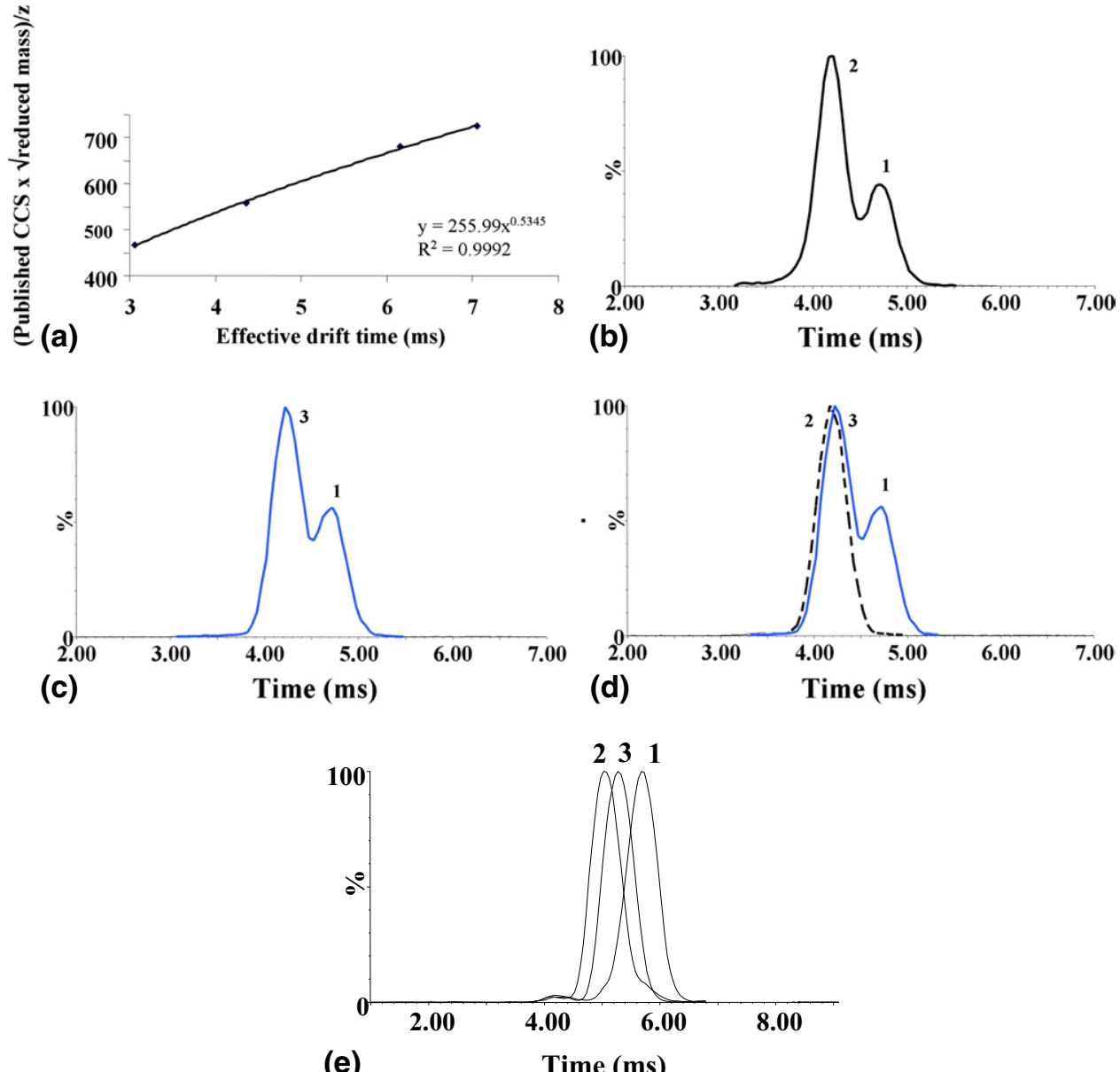

(e)

Time (ms)

Figure 2. (a) Traveling-wave ion mobility calibration curve of drift-time versus adjusted collision cross section of four tryptic hemoglobin peptides. A power curve of the form $y=a x^{b}$ is fitted to the data. (b) IM drift times of a mixture of complexes $\mathbf{2}$ and $\mathbf{1}$ (1:1 mixture); (c) IM drift times of complexes 3 and $\mathbf{1}$ (1:1 mixture); (d) IM drift times of the complexes 3 and $\mathbf{1}$ (solid line) overlaid with IM drift time of complex 2 (dotted line) highlighting the small differences in arrival time; and (e) overlaid individual drift times of the three isomeric $[\mathrm{M}-\mathrm{HCl}]^{+}$ions. (Note: this mobility separation was performed with a wave amplitude of $20 \mathrm{~V}$ and thus recalibrated for CCS determination.)

drift time of the mixture of $\mathbf{3}$ and $\mathbf{1}$ (solid line), highlighting the small but reproducible difference in arrival time of complexes $\mathbf{2}$ and $\mathbf{3}$. These data show that it is possible to separate a mixture of $\mathbf{1}$ and $\mathbf{3}$ or a mixture of $\mathbf{1}$ and $\mathbf{2}$, although similarities in conformation (shape) of 2 and 3 would render them difficult to separate using the present ion mobility approach.

The difference in conformation of $\mathbf{1}$ (more elongated) compared with that of $\mathbf{2}$ and $\mathbf{3}$ (more compact) correlates with the different (increased) anticancer activity of 1 compared with the other two complexes [15]. See Section S3 of the supplementary material for further discussion. The drift times for each of the molecular ions of the three isomeric complexes were converted into CCS values as described in Section S2 of the supplementary material and references therein, as shown in Table 1. Table 1 shows the experimentally derived CCS values for the $[\mathrm{M}-\mathrm{HCl}]^{+}$species. The overlaid mobility spectrum obtained for $\mathrm{m} / \mathrm{z} 391.1$ for each of the complexes is shown in Figure 2e. It can be seen that isomeric ions $\left[\mathrm{M}-\mathrm{HCl}^{+}\right.$detected at $\mathrm{m} / \mathrm{z}$ 391.1 for $\mathbf{2}$ and $\mathbf{3}$ are better resolved than the $[\mathrm{M}]^{+}$ions. A difference in drift time of $0.25 \mathrm{~ms}$ was observed between 2 and 3 for the isomeric $\left[\mathrm{M}-\mathrm{HCl}^{+}\right.$ions

Table 1. Comparison of the CCS values of complexes 1-3 obtained using T-wave ion mobility measurements and MOBCAL calculations

\begin{tabular}{ccccc}
\hline & \multicolumn{4}{c}{$[\mathrm{M}]^{+}$calculated CCS $\left(\AA^{2}\right)$} \\
\cline { 2 - 5 } Complex & $\begin{array}{c}\text { T-Wave } \\
( \pm 0.5 \%)\end{array}$ & $\begin{array}{c}\text { MoBCAL } \\
\text { Projection } \\
\text { Approx. }\end{array}$ & $\begin{array}{c}\text { MOBCAL } \\
\text { Trajectory } \\
\text { Method }\end{array}$ & $\begin{array}{c}\text { MOBCAL } \\
\text { Exact Hard } \\
\text { Sphere }\end{array}$ \\
\hline \hline $\mathbf{1}$ & 120.6 & 121.5 & $121.3( \pm 7.3 \%)$ & 130.0 \\
$\mathbf{2}$ & 113.0 & 112.2 & $112.9( \pm 3.5 \%)$ & 121.8 \\
$\mathbf{3}$ & 113.6 & 116.1 & $117.2( \pm 4.7 \%)$ & 125.1 \\
Following loss of HCl $[\mathrm{M}-\mathrm{HCl}]^{+}$ & & \\
$\mathbf{1}$ & 115.3 & 119.3 & $118.1( \pm 8.2 \%)$ & 126.7 \\
$\mathbf{2}$ & 106.6 & 109.3 & $108.2( \pm 3.6 \%)$ & 117.7 \\
$\mathbf{3}$ & 110.0 & 114.3 & $114.9( \pm 4.7 \%)$ & 122.4 \\
\hline
\end{tabular}


compared with a difference of only $0.05 \mathrm{~ms}$ for the respective isomeric $[\mathrm{M}]^{+}$ions detected at $\mathrm{m} / \mathrm{z}$ 427.1. Upon molecular modeling visualization of the $\mathrm{HCl}$ neutral loss species, it was observed that the loss of a chlorine atom from the parent terphenyl complex had a dramatic effect on conformation and is reflected in the observed drift times and the T-wave-derived CCSs.

No crystal structures have been obtained for the $[\mathrm{M}-\mathrm{HCl}]^{+}$isomers because such coordinatively unsaturated complexes (5-coordinate) would not be stable under crystallization conditions. However, energyminimized refined structures were obtained, allowing MOBCAL theoretical CCSs to be determined for comparison with the T-wave-derived values (Table 1).

In summary the experimentally derived $\mathrm{T}$-wave CCSs were compared with the MOBCAL-derived CCS values (Table 1). It can be seen that the CCS calculations obtained using MOBCAL are in excellent agreement with experimentally derived values and show a similar trend with the experimental data for the CCS measurements obtained using IM.

\section{Conclusion}

Here we have shown for the first time that lowmolecular-weight isomeric ruthenium(II) terphenyl anticancer complexes can be differentiated as a function of their structures in the gas phase using ion mobility spectrometry. Theoretical CCS values show a trend similar to that of the experimentally derived data. The drift times obtained for the $\mathrm{m} / \mathrm{z} 427.1$ species from a mixture of complexes 2 and 1 and the mixture of complexes $\mathbf{3}$ and $\mathbf{1}$ showed significant differences, whereas similarities in the conformations of $\mathbf{2}$ and $\mathbf{3}$ render them more difficult to separate under the present experimental conditions. The differences in shape and mobility correlate with the reported differences in anticancer activity. Complexes 2 and 3 show similar but reduced anticancer activity compared with the more potent complex 1 .

The CCSs of the three isomeric species were obtained by calibration of the T-wave mobility device using known CCS values of singly charged tryptic peptide ions formed from an human hemoglobin digest. The T-wave mobility-derived CCS measurements were in excellent agreement with theory. The data reported here show that ion mobility mass spectrometry can provide quantitative data on the molecular shape and mobility of candidate anticancer complexes and other isomeric complexes, contributing to our understanding of structure-activity relationships and to the drug design process.

\section{Acknowledgments}

We thank the Warwick Research Development Fund for a grant (fellowship for JPW) and members of EC COST Action D39 for stimulating discussions.

\section{Appendix A Supplementary Material}

Supplementary material associated with this article may be found in the online version at doi:10.1016/ j.jasms.2009.02.016.

\section{References}

1. Colton, R.; D'Agostino, A.; Traeger, J. C. Electrospray Mass Spectrometry Applied to Inorganic and Organometallic Chemistry. Mass Spectrom. Rev. 1995, 14, 79-106.

2. Henderson, W.; Nicholson, B. K.; McCaffrey, L. J. Applications of Electrospray Mass Spectrometry in Organometallic Chemistry. Polyhedron 1998, 17, 4291-4313.

3. Traeger, J. C. Electrospray Mass Spectrometry of Organometallic Compounds. Int. J. Mass Spectrom. 2000, 200, 387-401.

4. Iannitti-Tito, P.; Weimann, A.; Wickham, G.; Sheil, M. M. Structural Analysis of Drug-DNA Adducts by Tandem Mass Spectrometry. Analyst 2000, 125, 627-634.

5. Esteban-Fernandez, D.; Canas, B.; Pizzaro, I.; Palacios, M. A.; GomezGomez, M. M. SEC-ICP-MS and ESI-MS as Tools to Study the Interaction between Cisplatin and Cytosolic Biomolecules. J. Anal. Atomic Spectrom. 2007, 22, 1113-1121.

6. Guo, Z.; Sadler, P. J. Metals in Medicine. Angew. Chem. Int. Ed. 1999, 38, 1512-1531.

7. Bruijnincx, P. C. A.; Sadler, P. J. New Trends for Metal Complexes with Anticancer Activity. Curr. Opin. Chem. Biol. 2008, 12, 197-206.

8. Carr, T. W. Plasma Chromatography of Isomeric Dihalogenated Benzene. J. Chromatogr. Sci. 1977, 15, 85-88.

9. Karpas, Z.; Cohen, M. J.; Stimac, R. M.; Wernlund, R. F. On the Effects of the Structure and Charge Distribution on the Mobility of Ions. Int. J. Mass Spectrom. 1986, 74, 153-159.

10. Wu, C.; Siems, W. F.; Klasmeier, J.; Hill, H. H. Separation of Isomeric Peptides Using Electrospray Ionisation/High Resolution Ion Mobility Spectrometry. Anal. Chem. 2000, 72, 391-395.

11. Dwivedi, P.; Bendiak, B.; Clowers, B. H.; Hill, H. H. Rapid Resolution of Carbohydrate Isomers by Electrospray Ionisation Ambient Pressure Ion Mobility Spectrometry-Time-of-Flight Mass Spectrometry. J. Am. Soc. Mass Spectrom. 2007, 18, 1163-1175.

12. Pringle, S. D.; Giles, K.; Wildgoose, J. L.; Williams, J. P.; Slade, S. E.; Thalassinos, K.; Bateman, R. H.; Bowers, M. T.; Scrivens, J. An Investigation of the Mobility Separation of Some Peptide and Protein Ions Using a New Hybrid Quadrupole/Travelling Wave IMS/OA-ToF Instrument. Int. J. Mass Spectrom. 2007, 261, 1-12.

13. Giles, K.; Pringle, S. D.; Worthington, K. R.; Little, D.; Wildgoose, J. L.; Bateman, R. H. Applications of a Traveling Wave-Based Radio-FrequencyOnly Stacked Ring Ion Guide. Rapid Commun. Mass Spectrom. 2004, 18, 2401-2414.

14. Williams, J. P.; Scrivens, J. H. Coupling Desorption Electrospray Ionization and Neutral Desorption/Extractive Electrospray Ionization with a Travelling-Wave Based Ion Mobility Mass Spectrometer for the Analysis of Drugs. Rapid Commun. Mass Spectrom. 2008, 22, 187-196.

15. Bugarcic, T.; Nováková, O.; Halámiková, A.; Zerzánková, L.; Vrána, O.; špárková, J.; Habtemariam, A.; Parsons, S.; Sadler, P. J.; Brabec, V. Cytotoxicity, Cellular Uptake, and DNA Interactions of New Monodentate Ruthenium(II) Complexes Containing Terphenyl Arenes. J. Med. Chem. 2008, 51, 5310-5319.

16. Foloppe, N.; Mackerell, A. D. All-Atom Empirical Force Field for Nucleic Acids: I. Parameter Optimization Based on Small Molecule and Condensed Phase Macromolecular Target Data. J. Comp. Chem. 2000, 21, 86-104.

17. Mesleh, M. F.; Hunter, J. M.; Shvartsburg, A. A.; Schatz, G. C.; Jarrold, M. F. Structural Information from Ion Mobility Measurements: Effects of the Long-Range Potential. J. Phys. Chem. 1996, 100, 16082-16086.

18. Smith, W.; Yong, C. W.; Rodger, P. M. DL_POLY: Application to Molecular Simulation. Mol. Simul. 2002, 28, 385-471.

19. Jarrold, M. F. Website http://www.indiana.edu/ nano/Software/ mobcal.txt.

20. Nováková, O.; Chen, H.; Vrána, O.; Rodger, A.; Sadler, P. J.; Brabec, V. DNA Interactions of Monofunctional Organometallic Ruthenium(II) Antitumor Complexes in Cell-Free Media. Biochemistry 2003, 42, 1154411554.

21. Chen, H. M.; Parkinson, J. A.; Parsons, S.; Coxall, R. A.; Gould, R. O.; Sadler, P. J. Organometallic Ruthenium(II) Diamine Anticancer Complexes: Arene-Nucleobase Stacking and Stereospecific Hydrogen-Bonding in Guanine Adducts. J. Am. Chem. Soc. 2002, 124, 3064-3082. 